\title{
RESEARCH
}

\section{The OPALS Major Trauma Study: impact of advanced life-support on survival and morbidity}

\author{
Ian G. Stiell MD MSc, Lisa P. Nesbitt MHA, William Pickett PhD, Douglas Munkley MD, \\ Daniel W. Spaite MD, Jane Banek CHIM, Brian Field MBA EMCA, Lorraine Luinstra-Toohey BScN MHA, \\ Justin Maloney MD, Jon Dreyer MD, Marion Lyver MD, Tony Campeau MAEd PhD, \\ George A. Wells PhD, for the OPALS Study Group
}

$\infty$

See related article page II7I

\section{ABSTRACT}

Background: To date, the benefit of prehospital advanced life-support programs on trauma-related mortality and morbidity has not been established

Methods: The Ontario Prehospital Advanced Life Support (OPALS) Major Trauma Study was a before-after systemwide controlled clinical trial conducted in 17 cities. We enrolled adult patients who had experienced major trauma in a basic life-support phase and a subsequent advanced life-support phase (during which paramedics were able to perform endotracheal intubation and administer fluids and drugs intravenously). The primary outcome was survival to hospital discharge.

Results: Among the 2867 patients enrolled in the basic lifesupport $(n=1373)$ and advanced life-support $(n=1494)$ phases, characteristics were similar, including mean age (44.8 v. 47.5 years), frequency of blunt injury ( $92.0 \%$ v. $91.4 \%$ ), median injury severity score (24 v. 22) and percentage of patients with Glasgow Coma Scale score less than 9 (27.2\% v. $22.1 \%)$. Survival did not differ overall $(81.1 \%$ among patients in the advanced life-support phase v. $81.8 \%$ among those in the basic life-support phase; $p=0.65$ ). Among patients with Glasgow Coma Scale score less than 9, survival was lower among those in the advanced life-support phase (50.9\% v. 60.0\%; $p=0.02)$. The adjusted odds of death for the advanced life-support $v$. basic life-support phases were nonsignificant (1.2, 95\% confidence interval 0.9-1.7; $p=0.16$ ).

Interpretation: The OPALS Major Trauma Study showed that systemwide implementation of full advanced life-support programs did not decrease mortality or morbidity for major trauma patients. We also found that during the advanced lifesupport phase, mortality was greater among patients with Glasgow Coma Scale scores less than 9. We believe that emergency medical services should carefully re-evaluate the indications for and application of prehospital advanced life-support measures for patients who have experienced major trauma.

Une version française de ce résumé est disponible à l'adresse www.cmaj.ca/cgi/content/full/I78/9/II4I/DCI

CMAJ 2008;178(9):114I-52
$\mathrm{E}$ ach year in the United States, an estimated 500000 adult patients are transported to hospital after experiencing major trauma. ${ }^{1,2}$ Major trauma can be described as life- or limb-threatening injury due to blunt force, penetrating injury or burn injury. Considering both frequency and associated mortality, major trauma is the second most important condition for children and the fourth most important condition for adults treated by emergency medical service providers. ${ }^{2}$ About $20 \%$ of these patients die, and many survivors are left with permanent disability.

Throughout most urban areas of the United States and Canada, paramedics provide prehospital advanced lifesupport to many of these critically injured patients. Advanced life-support protocols include advanced airway management (endotracheal intubation) and intravenous fluid therapy. In contrast, basic life-support providers administer oxygen, ventilate with a bag valve mask, and provide immobilization and dressings. The relative effectiveness of community-based advanced life-support programs for major trauma patients has not been clearly established, and there have been calls for larger and more rigorously designed studies. ${ }^{3-5}$

Endotracheal intubation in the field has not been proven to reduce mortality and morbidity among severely injured patients, and there are concerns that performing this difficult task under trying conditions may cause harm. ${ }^{6,7}$ The value of prehospital intravenous resuscitation has also been questioned. ${ }^{8,9}$ In addition, there are concerns that the on-scene time spent providing advanced life-support measures may ac-

From the Departments of Emergency Medicine (Stiell) and of Epidemiology and Community Medicine (Wells), University of Ottawa, Ottawa, Ont.; the Clinical Epidemiology Program, Ottawa Health Research Institute (Stiell, Nesbitt, Banek, Wells), Ottawa, Ont.; the Department of Emergency Medicine (Pickett), Queen's University, Kingston, Ont.; Greater Niagara Base Hospital (Munkley, Luinstra-Toohey), Niagara Falls, Ont.; the Department of Emergency Medicine (Spaite), University of Arizona, Tucson, Ariz.; Interdev Technologies (Field), Toronto, Ont.; Ottawa Base Hospital Program (Maloney), Ottawa, Ont.; the Division of Emergency Medicine (Dreyer), University of Western Ontario, London, Ont.; the Department of Family Medicine (Lyver), McMaster University, Hamilton, Ont.; and Emergency Health Services (Campeau), Ontario Ministry of Health and Long-Term Care, Toronto, Ont. 
tually delay life-saving expeditious transfer to the hospital and the operating room. ${ }^{10}$ To date, no large controlled clinical trials have been conducted to evaluate the impact of prehospital advanced life-support programs on trauma-related mortality and morbidity. ${ }^{3}$

As part of the Ontario Prehospital Advanced Life Support (OPALS) studies, we recently demonstrated that advanced life-support programs had no impact on the outcomes of patients who had experienced cardiac arrest, but they did lead to significant improvement in survival among patients with respiratory distress. ${ }^{11,12}$ The primary objective of the current study, the OPALS Major Trauma Study, was to assess any change in survival that might result from the systemwide introduction of prehospital advanced life-support programs in multiple cities with existing basic life-support programs provided through emergency medical services. We also evaluated the impact of advanced life-support on morbidity and processes of care.

Table 1: Characteristics of the $2867^{*}$ study patients obtained from prehospital and on-scene records (part 1)

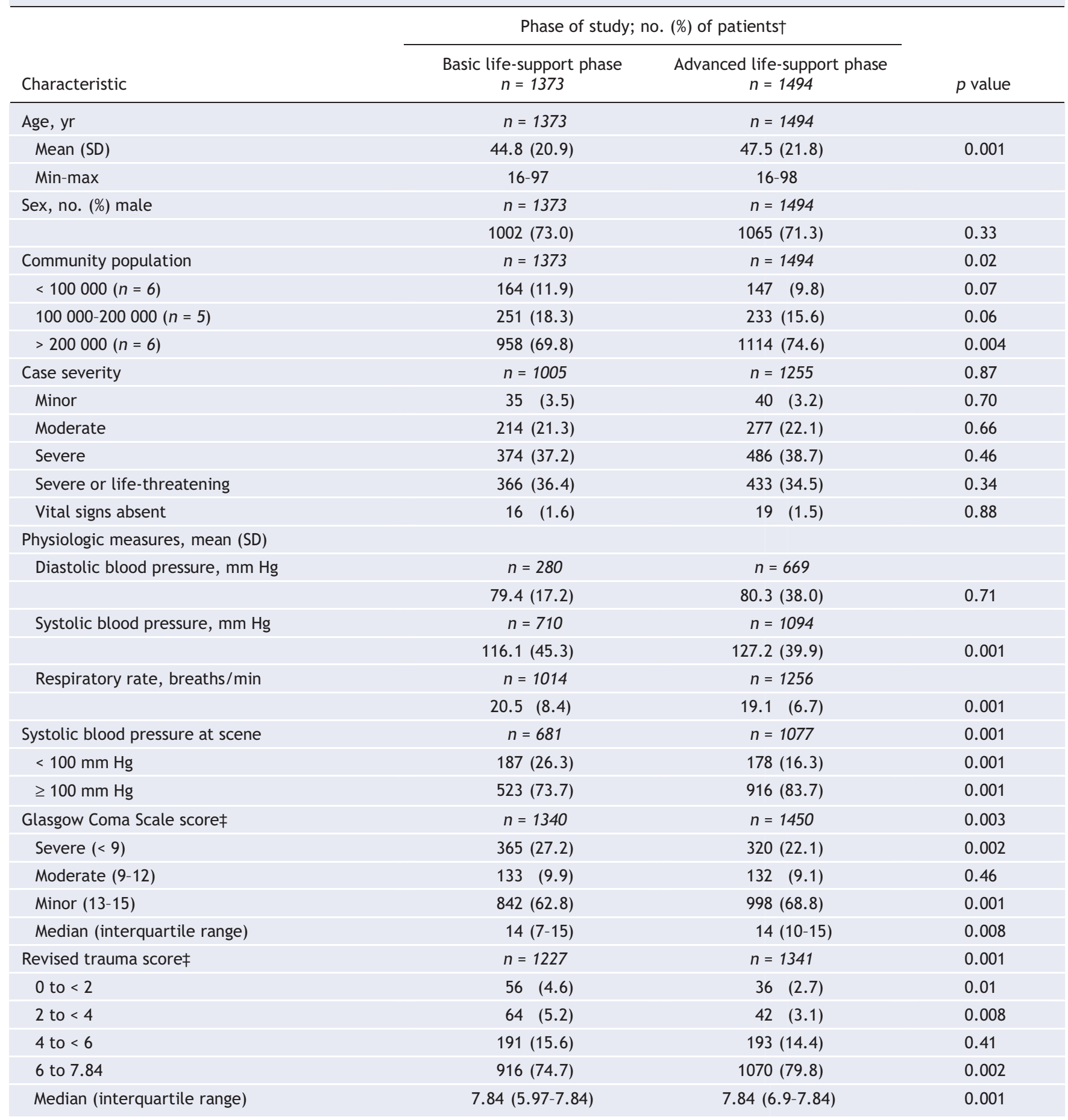




\section{Methods}

\section{Design}

We conducted a systemwide before-after controlled clinical trial, the unit of study being individual eligible patients with major trauma seen during 2 distinct phases: the basic life-support phase $\left(36\right.$ months) and the advanced life-support phase ${ }_{3} 6$ months). ${ }^{13}$ Patient data were pooled across multiple study cities, but the start date for each phase differed, as each community re- quired different periods to train paramedics to the advancedlife-support standard. The data-collection phases for each city were separated by intervening run-in periods to allow for training and system optimization. Detailed methods for the major trauma portion of the OPALS Study were published previously. ${ }^{13}$

\section{Setting}

We conducted the study in 17 cities within the province of Ontario, Canada, with medical oversight for emergency medical

Table 1: Characteristics of the $2867^{*}$ study patients obtained from prehospital and on-scene records (part 2)

\begin{tabular}{|c|c|c|c|}
\hline Characteristic & \multicolumn{2}{|c|}{ Phase of study; no. (\%) of patients $\dagger$} & $p$ value \\
\hline Nature of injury & $n=1371$ & $n=1494$ & 0.94 \\
\hline Blunt & $1262(92.0)$ & $1366(91.4)$ & 0.55 \\
\hline Penetrating & $80 \quad(5.8)$ & $89 \quad(6.0)$ & 0.89 \\
\hline \multirow[t]{2}{*}{ Extrication required } & $n=1329$ & $n=1472$ & \\
\hline & $234(17.6)$ & $303(20.6)$ & 0.05 \\
\hline Time intervals, min, median (interquartile range) & $n=1373$ & $n=1494$ & \\
\hline Call received to crew notified & $0.9 \quad(0.5-1.4)$ & $0.8 \quad(0.5-1.6)$ & 0.84 \\
\hline $\begin{array}{l}\text { Crew notified to vehicle stops - basic } \\
\text { life-support }\end{array}$ & $6.0 \quad(4.1-8.7)$ & $6.9 \quad(4.2-10.2)$ & 0.001 \\
\hline Crew notified to vehicle stops - first & $6.0 \quad(4.0-8.7)$ & $6.6 \quad(4.5-9.1)$ & 0.001 \\
\hline Vehicle stops to patient side & $2.0 \quad(1.0-2.0)$ & $2.0 \quad(2.0-2.0)$ & 0.001 \\
\hline Patient side to depart scene & $13.0 \quad(9.0-18.5)$ & $14.8(10.6-20.6)$ & 0.001 \\
\hline Depart scene to arrive hospital & $6.1 \quad(3.9-10.4)$ & $7.2(4.4-10.8)$ & 0.001 \\
\hline Total time on scene & $15.0(10.0-20.5)$ & $16.8(12.6-22.6)$ & 0.001 \\
\hline Total time, notified to arrive hospital & $29.7(23.0-40.1)$ & $34.2(26.5-43.9)$ & 0.001 \\
\hline $\begin{array}{l}\text { Prehospital interventions by emergency } \\
\text { medical service }\end{array}$ & $n=1373$ & $n=1494$ & \\
\hline Advanced life-support on scene & $35 \quad(2.5)$ & $1082(72.4)$ & 0.001 \\
\hline Ventilation & $137(10.0)$ & $180(12.0)$ & 0.10 \\
\hline \multirow[t]{2}{*}{ Intravenous line inserted } & & $n=1236$ & \\
\hline & - & $779(63.0)$ & - \\
\hline \multirow[t]{2}{*}{ Intravenous fluid bolus } & & $n=1236$ & \\
\hline & - & 144 (11.7) & - \\
\hline \multirow[t]{2}{*}{ Intravenous morphine } & & $n=1236$ & \\
\hline & - & $35 \quad(2.8)$ & - \\
\hline
\end{tabular}

Note: SD = standard deviation.

*Some analyses are based on fewer observations than the total $n$ for each phase because of missing data (indicated by $n$ values in columns 2 and 3 ). †Unless stated otherwise.

fGlasgow Coma Scale and revised trauma scores reflect the first available record, either prehospital or hospital. 
services provided by II provincial base-hospital programs. The total population was 2.5 million, with the population of individual cities varying from 20000 to 750000 . Two large cities in the jurisdiction, Toronto and Hamilton, were not included because they both had pre-existing advanced life-support response systems. Each of the participating centres was served by a provincial Central Ambulance Communications Centre, which provided electronic and synchronized dispatch information. The paramedics documented prehospital care on a standardized provincial ambulance call report form. During the basic lifesupport phase, each community provided a tiered response: firefighters first, followed by primary care paramedics who were trained to provide all basic life-support measures.

\section{Population}

The study population consisted of all patients 16 years of age or older who had been injured by any mechanism, whose injury severity score was more than $\mathrm{I} 2$, who had been transported by land ambulance and who had been treated at one of the I3 lead trauma hospitals in Ontario. Patients could have been transferred from a primary hospital or taken directly from the scene to the trauma hospital. Hospital and outcome data were available from the Ontario Trauma Registry Comprehensive Data Set. ${ }^{14}$ We abstracted prehospital information from ambulance call reports and the database of the provincial dispatch centre. Excluded were patients younger than 16 years, those whose injury had occurred more than 8 hours before the call to emergency medical services and those who were pronounced dead at the scene. The study received full approval by the Ottawa Hospital Research Ethics Board, and the requirement for informed consent was waived.

\section{Intervention}

The study intervention consisted of an advanced life-support program whereby 400 paramedics were trained to perform endotracheal intubation, insert intravenous lines and administer medications and fluids intravenously. The Ontario Ministry of Health and Long-Term Care funded this advanced life-support program and has estimated that the total cost of training and operational upgrades was $\$ 15.8$ million. All of these paramedics had previously completed a Io-month community college program and had several years of experience. For the study, the paramedics completed training to meet the Canadian Medical Association's Emergency Medical Technician Level III standards; this training involved 6 weeks of didactic instruction, 6 weeks of clinical instruction and a I2-week preceptorship (training in the field). To qualify for the advanced life-support phase of the OPALS Study, each community had to meet the following criteria for cardiac arrest patients: paramedics responded to $95 \%$ of cases, paramedics arrived at the scene within II minutes for $80 \%$ of cases, and paramedics successfully performed endotracheal intubation for $90 \%$ of cases. Of the original 20 communities considered for this study, 3 did not meet these standards and were excluded.

\section{Outcome measures}

The primary outcome, survival to hospital discharge, was defined as the patient leaving the hospital alive or being trans- ferred to a long-term care facility; we obtained these data from hospital records. In addition, we measured diseasespecific quality of life with the 7-level functional independence measure for survivors. ${ }^{15}$

\section{Data analysis}

The sample size available for analyzing the primary outcome (survival to hospital discharge) was determined from the number of available cases in the study communities before $(n=1373)$ and after ( $n=1494)$ introduction of advanced lifesupport services. Given a set of 4 assumptions (2-sided $\alpha=$ $0.05, \beta=0.20$, baseline survival $=8 \mathrm{I} .9 \%$, and I:I.09 ratio of patients in the 2 study phases), we estimated that the minimum absolute difference in the primary outcome that was detectable between the study phases was 3.8\% $(85.7 \%$ advanced life-support v. 8I.9\% basic life-support). We tested the primary hypothesis of improvement in survival rates from the basic life-support phase to the advanced life-support phase by $\chi^{2}$ analysis techniques. All $p$ values are 2 -tailed.

We captured data for the following potential confounders: demographic characteristics (age, sex, community); prehospital variables (case severity, systolic and diastolic blood pressure, respiratory rate, Glasgow Coma Scale score, revised trauma score ${ }^{16}$ nature of injury, requirement for extrication, the response-time intervals "crew notified to vehicle stops," "vehicle stops to patient side," "patient side to depart scene" and "depart scene to arrive hospital emergency department"); measures of specific advanced life-support interventions (ventilation, oral and nasal intubation, intravenous administration of fluids, administration of morphine); and hospital variables from the records of the lead trauma hospital (Glasgow Coma Scale score, revised trauma score, injury severity score, abbreviated injury score by body region, ${ }^{17}$ external cause of injury code from the gth revision of the International Classification of Diseases, direct admission or transfer from another primary or secondary hospital, intensive care). In cases during the second phase of the study where basic lifesupport and advanced life-support crews were both sent to the scene, the first response time or the shortest response interval was employed in analytical comparisons.

We assessed the match of injury severity between the OPALS Study patients and the reference group of the earlier Major Traum Outcome Study by phase using the " $M$ statistic," as described in trauma score and injury severity score methodology. ${ }^{18,19}$ The $M$ statistic ranges from o to I, with a value close to $\mathrm{I}$ indicating a good match and a value close to $o$ indicating a disparity in the injury severity match. We expressed the clinical importance of the difference between the observed (OPALS) and expected (Major Trauma Outcome Study) number of survivors as the " $W$ statistic," and we compared the mean increase or decrease in the number of survivors per 100 patients treated with norm expectations. We expressed the statistical significance of the difference in survival in the OPALS study population relative to the Major Trauma Outcome Study population with the " $Z$ statistic." Absolute $Z$ values exceeding I.96 indicate a statistically significant difference in observed v. predicted survival rates.

We compared outcomes between phases for the following 
Table 2: Characteristics of the $2867^{*}$ study patients obtained from records of lead trauma hospital

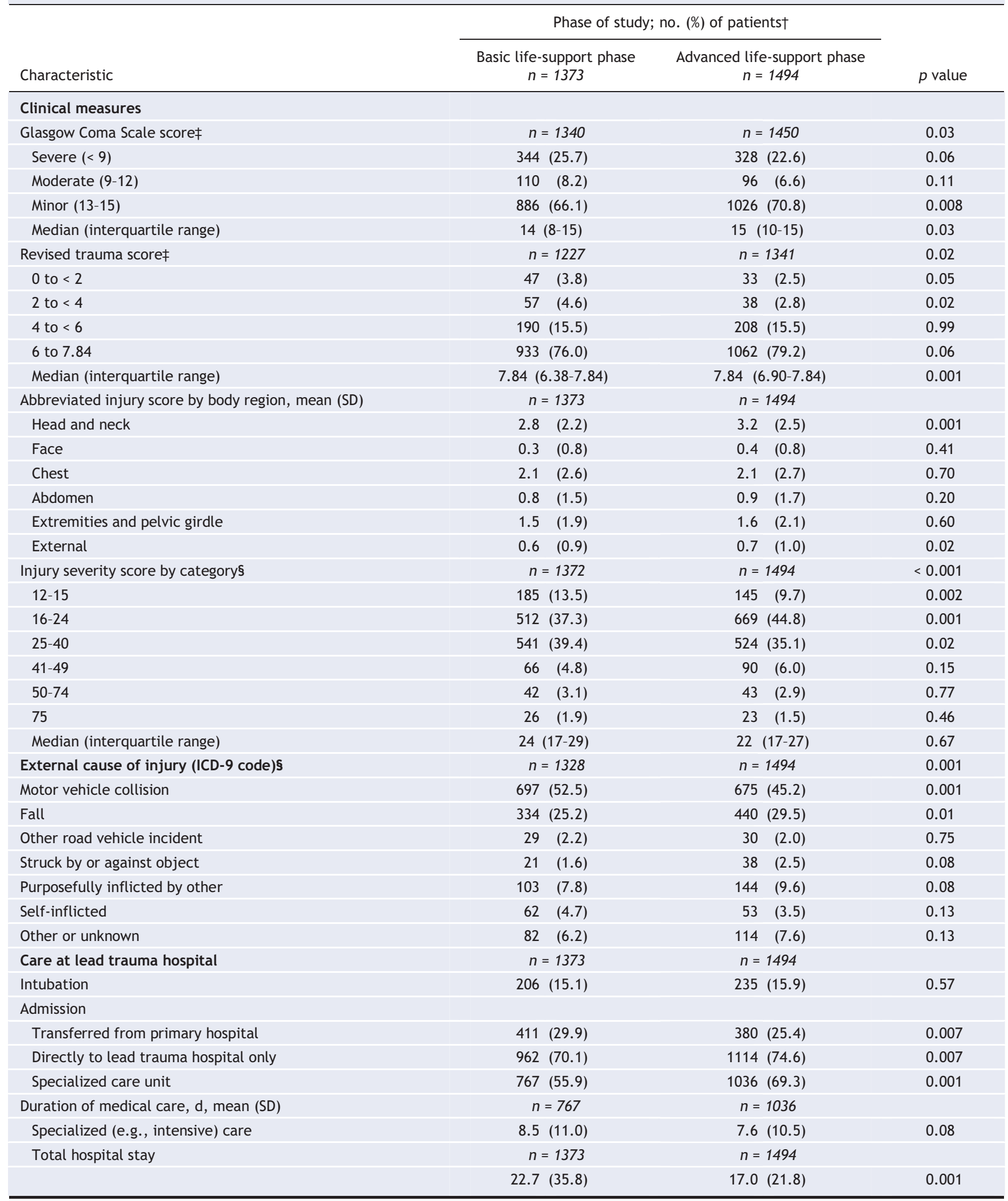

Note: ICD-9 = International Classification of Diseases, 9th revision.

*Some analyses are based on fewer observations than the total $n$ for each phase because of missing data (indicated by $n$ values in columns 2 and 3 ). †Unless stated otherwise.

fGlasgow Coma Scale and revised trauma scores reflect the lead hospital record or (if unavailable) the last prehospital or hospital record.

$\S$ Classified according to levels in the Multiple Trauma Outcome Study. ${ }^{19}$ 
a priori subgroups: community size, nature of injury, external cause of injury, injury severity, Glasgow Coma Scale score, systolic blood pressure, abbreviated injury score and patient age. We also developed a series of multiple logistic regression models to assess the effects of study interventions (study phase, advanced life-support on site, and specific advanced life-support interventions) on patient nonsurvival, while simultaneously controlling for confounders indicated by the trauma score and injury severity score methodology.

\section{Results}

A total of 2867 patients were enrolled during the basic lifesupport phase ( $n=1373$; total period July I, I992, to Feb. 28, I998) and advanced life-support phase ( $n=\mathrm{I} 494$; total period Feb. I, I998, and June 30, 2002) for all cities. Patients in the 2 phases were similar for most characteristics obtained from the prehospital (Table I) and trauma hospital (Table 2) records. Compared with patients in the basic life-support phase, those in the advanced life-support phase were slightly older and from larger communities, had higher mean systolic blood pressure and lower respiratory rates, and had less severe injuries as indicated by Glasgow Coma Scale scores and revised trauma scores. During the advanced life-support phase, $6.8 \%$ of patients were intubated, which represents a success rate of $71.8 \%$ of cases in which intubation was attempted. In addition, intravenous access was established in $63.0 \%$ of patients, which represents a success rate of $90.3 \%$ for all attempts. Overall, II. $7 \%$ of the patients received intravenous fluid bolus therapy. According to hospital records (Table 2), patients in the advanced life-support phase had less severe injuries (as indicated by Glasgow Coma Scale score, revised trauma score, abbreviated injury scale and injury severity score), were more likely to have had a fall and less likely to have been involved in a motor vehicle collision, and were more likely to have been directly admitted to the lead trauma hospital compared with patients in the basic life-support phase.

There was no substantial difference in overall survival to hospital discharge by study phase (8I.8\% for the basic lifesupport phase v. 8I.I\% for the advanced life-support phase; $p=0.65$ ) (Table 3 ). In addition, the proportion of early deaths, within 24 hours, did not differ. More patients in the advanced life-support phase than in the basic life-support phase were judged by the paramedics to have "improved en route to hospital" ( $5.3 \%$ v. I0.I $\%$; $p<0.00 \mathrm{I})$. There were no differences in morbidity between the phases, as indicated by the Glasgow outcome scale and functional independence

Table 3: Survival and other clinical outcomes during the 2 study phases*

\begin{tabular}{|c|c|c|c|c|}
\hline \multirow[b]{2}{*}{ Outcome } & \multicolumn{2}{|c|}{ Phase of study; no. (\%) of patients† } & \multirow[b]{2}{*}{$p$ value } & \multirow[b]{2}{*}{$\begin{array}{l}\text { Absolute difference } \\
\qquad(95 \% \mathrm{Cl})\end{array}$} \\
\hline & $\begin{array}{l}\text { Basic life-support phase } \\
\qquad n=1373\end{array}$ & $\begin{array}{l}\text { Advanced life-support phase } \\
\qquad n=1494\end{array}$ & & \\
\hline Primary & $n=1373$ & $n=1494$ & & \\
\hline Survival to hospital discharge & $1123(81.8)$ & $1212(81.1)$ & 0.65 & $-0.7(-3.6$ to 2.2$)$ \\
\hline Death $<24 \mathrm{~h}$ & $n=1330$ & $n=1439$ & & \\
\hline \multicolumn{5}{|l|}{ Secondary } \\
\hline Condition en route to hospital & $n=1034$ & $n=1278$ & & \\
\hline Improved & $55 \quad(5.3)$ & $129(10.1)$ & 0.001 & 4.8 (2.6 to 7.0$)$ \\
\hline Worsened & $841(81.3)$ & $1065(83.3)$ & 0.21 & $2.0(-1.2$ to 5.2$)$ \\
\hline No change & $129(12.5)$ & $76 \quad(5.9)$ & 0.001 & $-6.5(-9.0$ to 4.1$)$ \\
\hline Moderate disability & $68(10.8)$ & $56 \quad(9.4)$ & 0.40 & $-1.5(-4.9$ to 2.0$)$ \\
\hline Severe disability & $103(16.4)$ & 119 (19.9) & 0.11 & $3.5(-0.9$ to 7.9$)$ \\
\hline Vegetative state & 11 & $12(2.0)$ & 0.73 & $0.3(-1.4$ to 1.9$)$ \\
\hline Death & $176(28.0)$ & $177(29.6)$ & 0.53 & $1.6(-3.1$ to 6.8$)$ \\
\hline $\begin{array}{l}\text { Functional independence measure, } \\
\text { mean (SD) }\end{array}$ & $n=762$ & $n=990$ & & \\
\hline At discharge & $95.0(28.6)$ & $94.2(28.2)$ & 0.54 & $-0.8(-3.5$ to 1.9$)$ \\
\hline \multirow[t]{2}{*}{ At 6 mo after discharge } & $n=455$ & $n=692$ & & \\
\hline & $115.3(21.0)$ & $116.2(20.2)$ & 0.47 & $0.9(-1.6$ to 3.3$)$ \\
\hline
\end{tabular}

Note: $\mathrm{Cl}=$ confidence interval.

*Some analyses are based on fewer observations than the total $n$ for each phase because of missing data (indicated by $n$ values in columns 2 and 3 ).

tUnless stated otherwise. 
Table 4: Survival to hospital discharge (primary outcome) among clinically important subgroups

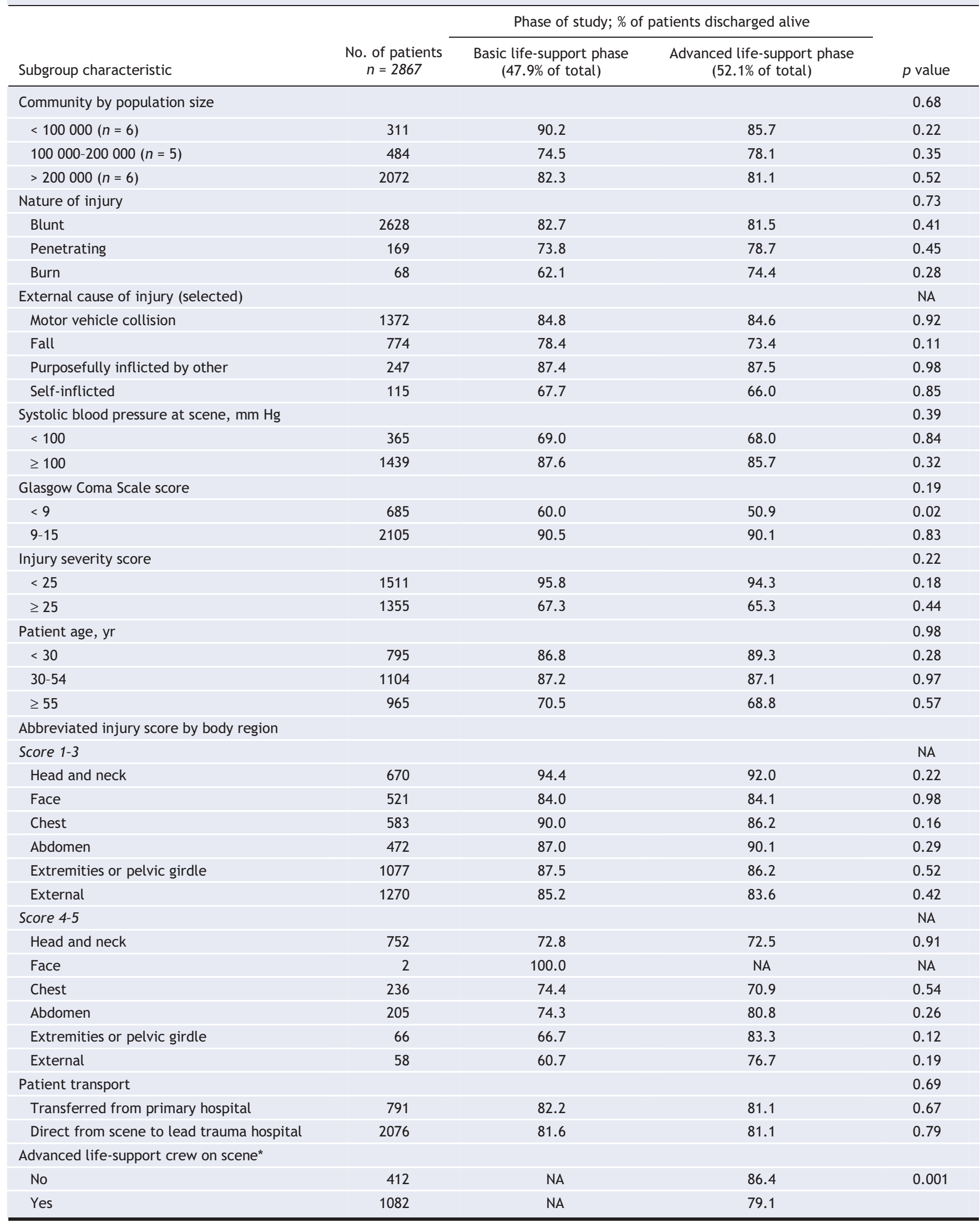

Note: $\mathrm{NA}=$ not applicable.

*Comparison of survival between patients with and without advanced life-support crew on scene, for the advanced life-support phase only. 
Table 5: Exploratory univariable association of patient and emergency medical services factors with survival to hospital discharge for 2866* patients with major trauma

\begin{tabular}{|c|c|c|c|}
\hline Characteristic & \multicolumn{2}{|c|}{ Survival; median (interquartile range)† } & $p$ value \\
\hline Patient & $n=2334$ & $n=532$ & \\
\hline Age, yr, mean (SD) & $43.8(20.2)$ & $56.6(23.3)$ & $<0.001$ \\
\hline Sex, no. (\%) males & $1656(71.0)$ & $349(65.6)$ & 0.08 \\
\hline Glasgow Coma Scale score & $n=2282$ & $n=508$ & \\
\hline Initial & $15(12-15)$ & $6 \quad(3-14)$ & $<0.001$ \\
\hline Final & $15(13-15)$ & $5.5(3-14)$ & $<0.001$ \\
\hline Revised trauma score & $n=2148$ & $n=420$ & \\
\hline Initial & $7.84(6.90-7.84)$ & $5.68(3.29-7.84)$ & $<0.001$ \\
\hline Emergency medical services & $n=2334$ & $n=532$ & \\
\hline Time from receipt of call to patient side, min & $9.3(7.0-13.0)$ & $8.8(7.0-11.8)$ & 0.008 \\
\hline Advanced life support phase of study, no. (\%) & $1212(51.9)$ & $282(53.0)$ & 0.67 \\
\hline Advanced life support at scene, no. (\%) & $876(37.5)$ & $233(43.8)$ & 0.008 \\
\hline Intubation in field, no. (\%) & $35 \quad(1.5)$ & $67(12.6)$ & $<0.001$ \\
\hline Intravenous fluid bolus administered in field, no. (\%) & $107(4.6)$ & $37(7.0)$ & 0.03 \\
\hline
\end{tabular}

*Some analyses are based on fewer observations because of missing data (indicated by $n$ values in columns 2 and 3 ).

tUnless stated otherwise.

measure at discharge and 6 months after discharge.

For most of the a priori subgroups examined, there was also no difference in survival to hospital discharge by study phase (Table 4). The exception were the 598 cases with an initial Glasgow Coma Scale score of less than 9, for whom survival was lower in the advanced life-support phase than in the basic life-support phase (60.1\% v. 51.2\%; $p=0.03$ ). Within the advanced life-support phase, survival was lower for cases in which an advanced life-support crew attended the trauma scene than for those attended by basic life-support crews only ( $86.4 \%$ for basic life-support v. $79.1 \%$ for advanced lifesupport; $p<0.00 \mathrm{I})$. The trauma cases in both phases of this study were more severe than norms from the Major Trauma Outcome Study $(M=0.67$ and 0.70 for basic and advanced life-support phases, respectively). The number of survivors in each phase of the OPALS Study was not substantially different from that predicted by Major Trauma Outcome Study norms ( $Z=0.72$ for basic life-support phase, $Z=-0.62$ for advanced life-support phase).

To better understand the factors influencing survival, we compared survivors with nonsurvivors (Table 5) and then conducted several logistic regression analyses to assess the effects of study interventions on patient mortality while controlling for potential confounding variables (Figure I, Figure 2, Figure 3, Figure 4; Appendix I, available online at www .cmaj.ca/cgi/content/full/I78/9/II4I/DC2). In all models, poorer survival was associated with older age, higher injury severity score and lower revised trauma score (i.e., more severe). We found that the adjusted odds ratio (OR) for mortality between the advanced life-support and basic life-support phases was not significant when we used the revised trauma score obtained from the trauma hospital (adjusted OR I.2, 95\% confidence interval [CI] 0.9-I.7; Figure I), but it was significant when we used the prehospital revised trauma score (adjusted OR I.4, 95\% CI I.0-I.9; Figure 2). The presence of advanced life-support providers at the scene was associated with increased mortality (adjusted OR I.5, 95\% CI I.I-2.0; Figure 3). In addition, intubation in the field was associated with increased mortality (adjusted OR 2.8, 95\% CI r.6-5.0; Figure 4), and intravenous fluid therapy was associated with no benefit (adjusted OR o.8, 95\% CI 0.4-I.4).

\section{Interpretation}

In this controlled clinical trial, we found that the systemwide implementation of prehospital advanced life-support did not decrease mortality or morbidity among major trauma victims. Despite the large sample, controlled design and multiple approaches to the analysis, we found no evidence of benefit in any clinically relevant subgroup of patients. To the contrary, the evidence suggested that patients with Glasgow Coma Scale scores less than 9 had worse survival during the ad- 
vanced life-support phase than during the basic life-support phase. Our findings support those who believe that definitive trauma care is best provided in the operating room and that prehospital interventions may be associated with increased complications or may delay transfer to hospital.

Controlled clinical trials of critically injured patients are difficult to conduct, particularly in the out-of-hospital setting, and observers have called for better evidence from more rigorous studies..$^{3-5}$ Previous evaluations of advanced lifesupport programs have generally had small numbers or have used observational methods. ${ }^{20-26}$ These studies generally found no support for prehospital advanced life-support measures in major trauma. Although our study evaluated the package of interventions that is considered part of advanced life-support protocols, endotracheal intubation and intravenous fluid administration were the dominant elements of the protocols of care. We documented higher mortality among patients undergoing prehospital endotracheal intubation even after controlling for age, injury severity and physiologic measures. It seems intuitive that intubation would help some trauma patients in the field, but there is surprisingly little evidence to support aggressive airway management by paramedics. Multiple studies have found no benefit from paramedic intubation of patients with head injury. ${ }^{23,27-30}$

$\begin{array}{ll}\text { Outcome } & \text { OR }(95 \% \mathrm{Cl}) \\ \text { Age, per } 10 \mathrm{yr} & 1.8(1.7-2.0) \\ \text { Injury severity score, per } 10 \text { units } & 1.9(1.6-2.2) \\ \text { Revised trauma score (final), }{ }^{*} \text { per unit } & 0.5(0.4-0.5) \\ \text { Call time, } \dagger \text { per minute } & 1.0(1.0-1.0) \\ \text { Advanced v. basic life-support phase } & 1.2(0.9-1.7)\end{array}$

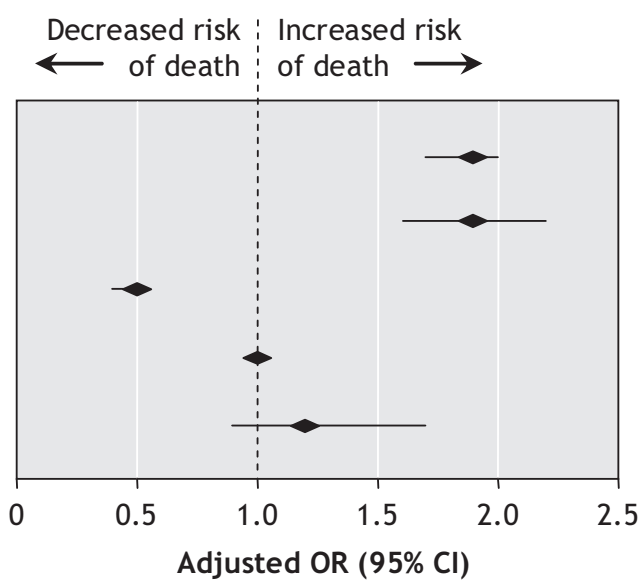

Figure 1: Adjusted odds ratios (ORs) and $95 \%$ confidence intervals (Cls) evaluating factors associated with mortality at hospital discharge. Model incorporates study phase and final (hospital) revised trauma score as predictors of mortality. Goodness-of-fit: $p>0.20$. *Final assessment of revised trauma score represents value from lead trauma hospital; if missing, the value from the scene was used. †Time from call received to arrival of crew at patient side.

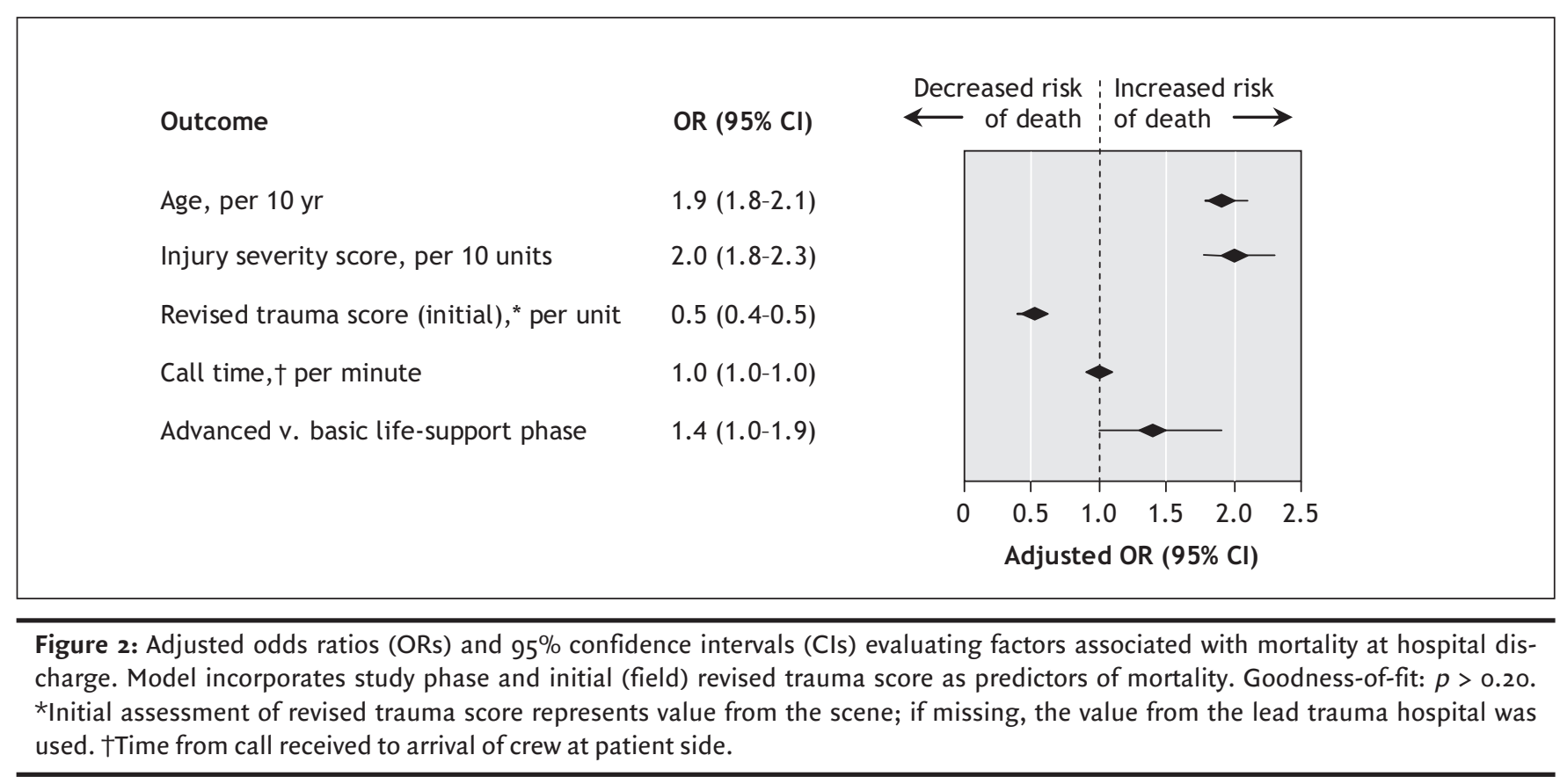


Other observational studies have suggested worse outcomes for patients with head injury who are intubated in the field. ${ }^{31,32}$ Rapid-sequence intubation techniques that employ neuromuscular blockade are particularly controversial, and expectations of benefit have not been confirmed by controlled studies. ${ }^{6,733-38}$ Three retrospective studies suggested that field intubation by ground or aeromedical paramedics was associated with better survival among patients with traumatic brain injury. ${ }^{33-35}$ These expectations of benefit have not been con- firmed by controlled studies. In addition, ours was the first large-scale controlled study to evaluate intravenous fluid therapy in patients with blunt trauma and head injury, but no benefit was observed. Lack of effectiveness of intravenous fluid therapy has been previously demonstrated, especially for patients with penetrating trauma to the torso..$^{8,9,39,40}$

The strengths of our study include the large number of patients, the involvement of communities of differing size across a broad geographic area and a controlled design that
Outcome

OR $(95 \% \mathrm{Cl})$

Age, per $10 \mathrm{yr}$

$1.9(1.8-2.1)$

Injury severity score, per 10 units

Revised trauma score (initial), ${ }^{*}$ per unit

Call time, $\uparrow$ per minute

Advanced life-support at scene
$2.0(1.8-2.3)$

$0.5(0.4-0.5)$

$1.0(1.0-1.0)$

$1.5(1.1-2.0)$

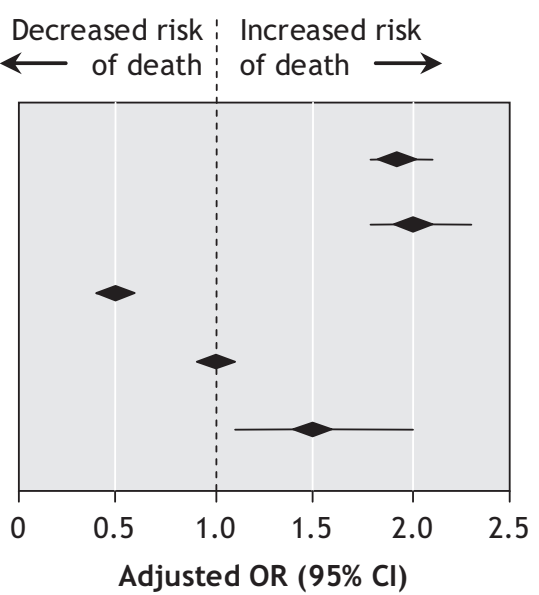

Figure 3: Adjusted odds ratios (ORs) and $95 \%$ confidence intervals (Cls) evaluating factors associated with mortality at hospital discharge. Model incorporates advanced life-support provided at the scene as predictor of mortality. Goodness-of-fit: $p>0.20$. *Initial assessment of revised trauma score represents value from the scene; if missing, the value from the lead trauma hospital was used. †Time from call received to arrival of crew at patient side.

\section{Outcome}

Age, per $10 \mathrm{yr}$

Injury severity score, per 10 units

Glasgow Coma Scale score (initial), ${ }^{*}$ per unit

Systolic blood pressure (initial), ${ }^{*}$ per unit

Call time, per minute

Intubation at scene

Intravenous fluid at scene

\section{OR $(95 \% \mathrm{Cl})$}

$1.8(1.7-2.0)$

$2.0(1.8-2.3)$

$0.8(0.8-0.8)$

$1.0(1.0-1.0)$

$1.0(1.0-1.0)$

$2.8(1.6-5.0)$

$0.8(0.4-1.4)$
Decreased risk, Increased risk

$\longleftarrow$ of death of death $\longrightarrow$

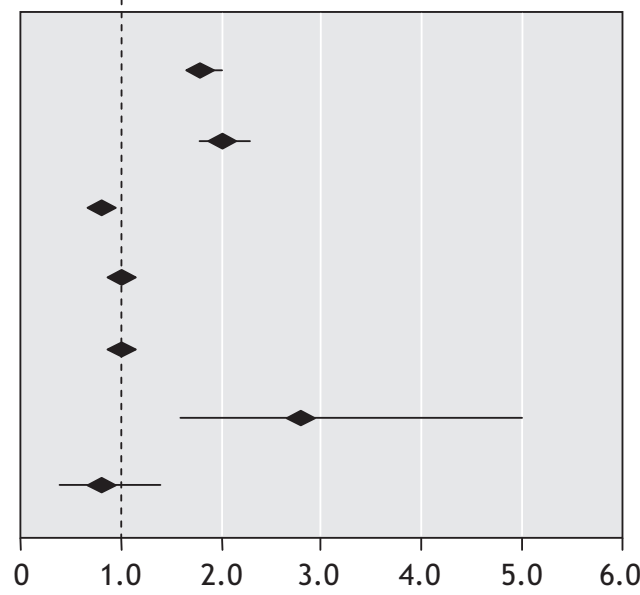

Adjusted OR (95\% Cl)

Figure 4: Adjusted odds ratios (ORs) and 95\% confidence intervals (Cls) evaluating factors associated with mortality at hospital discharge. Model incorporates advanced life-support interventions as predictors of mortality. Goodness-of-fit: $p>0.20$. ${ }^{*} \mid$ nitial assessments of Glasgow Coma Scale score and systolic blood pressure represent values from the scene; if missing, the value from the lead trauma hospital was used. †Time from call received to arrival of crew at patient side. 
included a complete population-based sample. Training of the paramedics involved a standardized national curriculum and clinical training period. All trainees were experienced emergency medical technicians and had the benefit of a 6- to 36-month run-in period in which to perfect their skills. The paramedics were skilful at performing procedures in these difficult cases; we previously demonstrated that, for patients who had experienced cardiac arrest, these same paramedics were able to successfully intubate in $93.7 \%$ of cases and to start an intravenous line in $89.0 \% .{ }^{11}$ The crews arrived at scene in a timely fashion (median 6.6 minutes).

An important potential limitation is that this study was designed as a before-after controlled trial, rather than as a randomized trial. However, we do not believe that this undermines the validity of the findings. Randomization by patient was not possible, because the paramedics considered it unethical to randomly withhold potentially life-saving procedures from patients. Selection bias was minimized by the population-based approach, whereby all patients from the study communities who had been treated at the regional trauma centre were included. We are not aware of any important new therapies or any general societal increase in survival rates among patients experiencing major trauma during the study period. Nevertheless, multiple statistical approaches were taken to ensure the validity and robustness of our outcome measures.

The implications of this study are that community emergency medical services should carefully re-evaluate the use of advanced life-support measures for most trauma patients. Our data showed no benefit for any group of patients. Furthermore, we are concerned that the patients with head injury who had a Glasgow Coma Scale score of less than 9 appeared to have higher mortality during the advanced life-support phase than during the basic life-support phase. We note that, after controlling for age, injury severity and physiologic measures, intubation in the field had an odds ratio for mortality of 2.8. These data should lead to a re-evaluation of the indications for and application of advanced life-support measures in the field for trauma patients in urban areas. These findings cannot be extrapolated to either the care of trauma patients in rural settings or advanced life-support care for patients with nontraumatic conditions such as respiratory distress and chest pain. To prevent the deleterious effects of misplaced tubes, hypoxia and hypercapnea, prehospital intubation of trauma patients should always be accompanied by continuous pulse oximetry as well as end-tidal carbon dioxide monitoring and recording.

\section{Conclusion}

The implementation of full prehospital advanced life-support by trained paramedics was not associated with lower mortality rates relative to basic life-support measures for patients with major trauma. Furthermore, our evidence indicates that, for patients with suspected head injuries and a Glasgow Coma Scale score of less than 9, mortality was greater during the advanced life-support phase of the study than during the basic life-support phase. On the basis of these findings, we suggest that emergency medical services should carefully reevaluate the indications for and application of prehospital advanced life-support measures for patients with major trauma.

This article has been peer reviewed.

Competing interests: None declared.

Disclaimer: George Wells is a coauthor of this article. As a biostatistics consultant of CMAJ, he was not involved in the vetting of the manuscript before its acceptance.

Contributors: Ian Stiell and George Wells conceived the study, designed the trial and obtained research funding. Ian Stiell and Lisa Nesbitt supervised the conduct of the trial and data collection. Ian Stiell, Lisa Lesbitt, William Pickett, Douglas Munkley, Daniel Spaite, Jane Banek, Brian Field, Lorraine LuinstraToohey, Justin Maloney, Joe Dreyer, Marion Lyver and Tony Campeau recruited the participating centres and managed the data, including quality control. Ian Stiell, Lisa Nesbitt, William Pickett and George Wells provided statistical advice on study design and analyzed the data. Ian Stiell drafted the manuscript, and all of the authors contributed substantially to its revision and approved the final version. Ian Stiell takes responsibility for the paper as a whole.

Acknowledgements: We thank the OPALS Study Group investigators from the following network of Ontario base hospitals: Burlington: Matthew W. Stempien MD, Carrie I. Parkinson BScN; Cambridge: David Waldbillig MD, Kieran W. Ballah EMCA; Kingston: Gordon J. Jones MD, Mark R. Halladay EMCA; London: Kenneth A. Boyle EMCA; Ottawa: John P. Trickett BScN; Peterborough: Vincent Arcieri MD, John W. Fader BSc; Sarnia: Martin G.J. Lees MD, Dallas D. LaBarre EMCA; Sudbury: Robert S. Lepage MD, Sylvie Salminen EMCA; Thunder Bay: Andrew W. Affleck MD, Tara A. Tyson BAdmin; Windsor: James C. Fedoruk MD, Meikel Gobet EMCA.

This study was funded by peer-reviewed grants from the Emergency Health Services Branch of the Ontario Ministry of Health and Long-Term Care and the Canadian Health Services Research Foundation. These government agencies had no role in the study design; the collection, analysis or interpretation of data; the writing of the report; or the decision to submit the paper for publication.

We thank Julie Cummins for assistance with preparation of the manuscript. We also thank the other members of the OPALS Study Coordinating Centre: David Brisson and Tammy Beaudoin (research staff), Catherine Clement (editing), Irene Harris (administrative support), My-Linh Tran (programming) and Sheryl Domingo (data entry). We thank Cathy Francis of the Ontario Ministry of Health and Long-Term Care for her support, contributing staff members from our network of Ontario base hospitals and the many primary care and advanced care paramedics who participated in the OPALS Study.

Ian Stiell holds a Distinguished Professorship and a University Health Research Chair from the University of Ottawa.

\section{REFERENCES}

I. McCaig LF, Ly N. National Hospital Ambulatory Medical Care Survey: 2000 emergency department summary. Adv Data 2002;(326):I-30.

2. Maio RF, Garrison HG, Spaite DW, et al. Emergency Medical Services Outcomes Project I (EMSOP I): prioritizing conditions for outcomes research. Ann Emerg Med I999;33:423-32.

3. Spaite DW, Criss EA, Valenzuela TD, et al. Prehospital advanced life support for major trauma: critical need for clinical trials. Ann Emerg Med ig98;32:480-9.

4. Carrico CJ, Holcomb JB, Chaudry IH; PULSE Trauma Work Group. Scientific priorities and strategic planning for resuscitation research and life saving therapy following traumatic injury: report of the PULSE Trauma Work Group. Post Resuscitative and Initial Utility of Life Saving Efforts. Shock 2002;17:I65-8.

5. Lewis RJ. Prehospital care of the multiply injured patient: the challenge of figuring out what works. JAMA 2004;291:1382-4.

6. Spaite DW, Criss EA. Out-of-hospital rapid sequence intubation: Are we helping or hurting our patients? Ann Emerg Med 2003;42:729-30.

7. Zink BJ, Maio RF. Out-of-hospital endotracheal intubation in traumatic brain injury: outcomes research provides us with an unexpected outcome. Ann Emerg Med 2004;44:45I-3.

8. Bickell WH, Wall MJ, Pepe PE, et al. Immediate versus delayed fluid resuscitation for hypotensive patients with penetrating torso injuries. N Engl J Med r994;331:1105-9.

9. Pepe PE. Controversies in resuscitation: to infuse or not to infuse (2). Resuscitation 1996;31:7-10.

Io. Spaite DW, Tse DJ, Valenzuela TD, et al. The impact of injury severity and prehospital procedures on scene time in victims of major trauma. Ann Emerg Med I99I; 20:1299-305. 
II. Stiell IG, Wells GA, Field BJ, et al. Advanced cardiac life support in out-of-hospital cardiac arrest. NEngl J Med 2004;351:647-56.

I2. Stiell IG, Spaite DW, Field B, et al. Advanced life support for out-of-hospital respiratory distress. N Engl J Med 2007;356:2156-64.

I3. Stiell IG, Wells GA, Spaite DW, et al. The Ontario Prehospital Advanced Life Support (OPALS) Study Part II: rationale and methodology for trauma and respiratory distress patients. Ann Emerg Med I999;34:256-62.

I4. Pickett W, Simpson K, Brison RJ. Rates and external causes of head trauma in Ontario: analysis and review of Ontario Trauma Registry datasets. Chronic Dis Can 2004;25:32-4I.

I5. Stineman MG, Shea JA, Jette A, et al. The Functional Independence Measure: tests of scaling assumptions, structure and reliability across 20 diverse impairment categories. Arch Phys Med Rehabil I996;77:I10I-8.

I6. Champion HR, Sacco WJ, Copes WS, et al. A revision of the Trauma Score. $J$ Trauma I989;29:623-9.

I7. MacKenzie EJ. Injury severity scales: overview and directions for future research Am J Emerg Med I984;2:537-49.

I8. Boyd CR, Tolson MA, Copes WS. Evaluating trauma care: the TRISS method. Trauma Score and the Injury Severity Score. J Trauma 1987;27:370-7.

I9. Champion HR, Copes WS, Sacco WJ, et al. The Major Trauma Outcome Study: establishing national norms for trauma care. J Trauma I990;30:1356-65.

20. Jacobs LM, Sinclair A, Beiser A, et al. Prehospital advanced life support: benefits in trauma. J Trauma $1984 ; 24: 8-\mathrm{I} 3$

2I. Potter D, Goldstein G, Fung SC, et al. A controlled trial of prehospital advanced life support in trauma. Ann Emerg Med I988;17:582-8.

22. Cayten CG, Murphy JG, Stahl WM. Basic life support versus advanced life support for injured patients with an injury severity score of ro or more. J Trauma 1993;35 460-7.

23. Eckstein M, Chan L, Schneir A, et al. Effect of prehospital advanced life support on outcomes of major trauma patients. J Trauma 2000;48:643-8.

24. Liberman M, Mulder D, Sampalis JS. Advanced or basic life support for trauma: meta-analysis and critical review of the literature. J Trauma 2000;49:584-99.

25. Liberman M, Mulder D, Lavoie A, et al. Multicenter Canadian study of prehospital trauma care. Ann Surg 2003;237:153-6o.

26. Lee A, Garner A, Fearnside M, et al. Level of prehospital care and risk of mortality in patients with and without severe blunt head injury. Injury 2003;34:815-9.

27. Murray JA, Demetriades D, Berne TV, et al. Prehospital intubation in patients with severe head injury. J Trauma 2000;49:1065-70.

28. Bochicchio GV, Ilahi O, Joshi M, et al. Endotracheal intubation in the field does not improve outcome in trauma patients who present without an acutely lethal traumatic brain injury. J Trauma 2003:54:307-II.

29. Davis DP, Peay J, Sise MJ, et al. The impact of prehospital endotracheal intubation on outcome in moderate to severe traumatic brain injury. J Trauma 2005;58:933-9.

30. Gausche M, Lewis RJ, Stratton SJ, et al. Effect of out-of-hospital pediatric endotracheal intubation on survival and neurological outcome: a controlled clinical trial. JAMA 2000;6:783-90.

3I. Davis DP, Hoyt DB, Ochs $\mathrm{M}$, et al. The effect of paramedic rapid sequence intubation on outcome in patients with severe traumatic brain injury. J Trauma 2003:54:444-53.

32. Wang HE, Peitzman AB, Cassidy LD, et al. Out-of-hospital endotracheal intubation and outcome after traumatic brain injury. Ann Emerg Med 2004;44:439-50.

33. Winchell RJ, Hoyt DB. Endotracheal intubation in the field improves survival in patients with severe head injury. Trauma Research and Education Foundation of San Diego. Arch Surg 1997;132:592-7.

34. Bulger EM, Copass MK, Sabath DR, et al. The use of neuromuscular blocking agents to facilitate prehospital intubation does not impair outcome after traumatic brain injury. J Trauma 2005;58:718-24.

35. Davis DP, Peay J, Serrano JA, et al. The impact of aeromedical response to patients with moderate to severe traumatic brain injury. Ann Emerg Med 2005;46:115-22.

36. Katz SH, Falk JL. Misplaced endotracheal tubes by paramedics in an urban emergency medical services system. Ann Emerg Med 200I;37:32-7.

37. Dunford JV, Davis DP, Ochs M, et al. Incidence of transient hypoxia and pulse rate reactivity during paramedic rapid sequence intubation. Ann Emerg Med 2003; 42:72I-8.

38. Davis DP, Dunford JV, Poste JC, et al. The impact of hypoxia and hyperventilation on outcome after paramedic rapid sequence intubation of severely head-injured patients. J Trauma 2004;57:I-IO.

39. Kaweski SM, Sise MJ, Virgilio RW. The effect of prehospital fluids on survival in trauma patients. J Trauma I990;30:1215-9.

40. Cooper DJ, Myles PS, McDermott FT, et al. Prehospital hypertonic saline resuscitation of patients with hypotension and severe traumatic brain injury: a randomized controlled trial. JAMA 2004;29I:1350-7.

Correspondence to: Dr. Ian G. Stiell, Clinical Epidemiology Unit, Rm. F657, Ottawa Health Research Institute, The Ottawa Hospital - Civic Campus, 1053 Carling Ave., Ottawa ON $\mathrm{KIY}_{4}$ E9; fax 6I3 76I-535I; istiell@ohri.ca

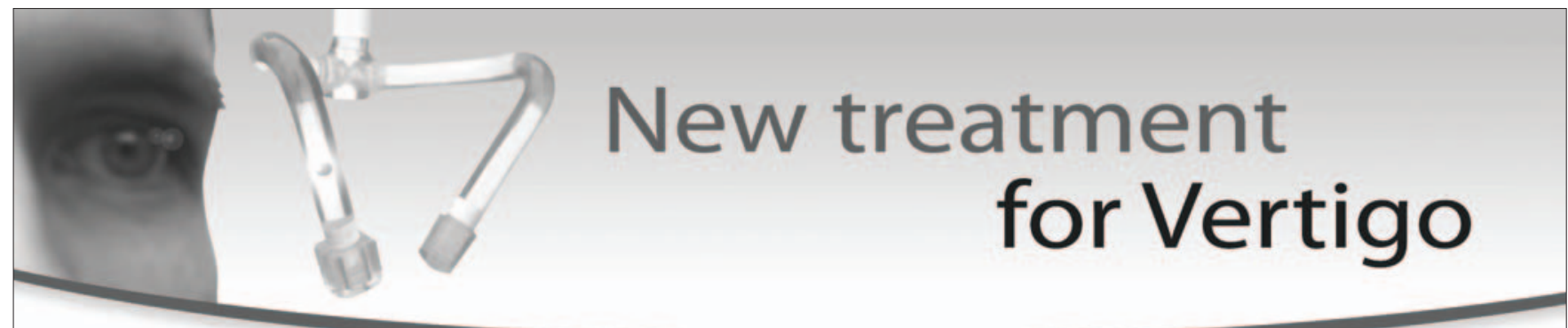

The DizzyFIX is a medical device that helps anyone easily treat vertigo due to BPPV.

Available in Canadian pharmacies and on-line now.

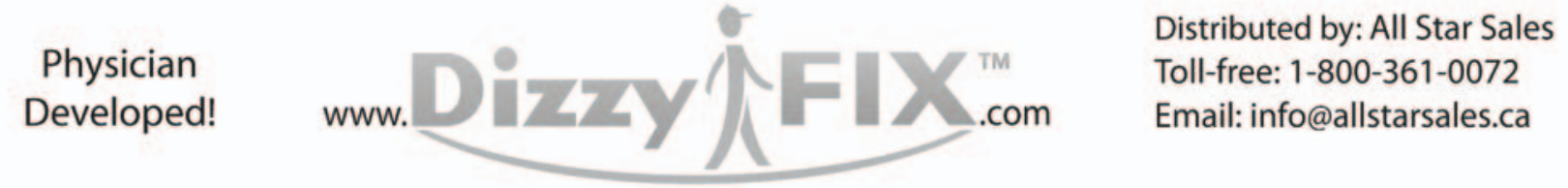

The DizzyFIX is a medical device according to rule $7(1)$ of the Medical Devices Regulations and has

been reviewed by the device licensing section of the Medical Devices Bureau of Health Canada 